\title{
A new approach to sensitivity climatologies: the DTS-MEDEX-2009 campaign
}

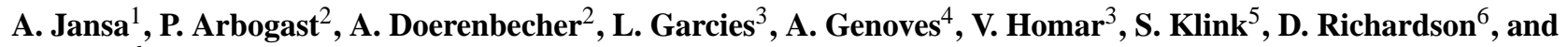 \\ C. Sahin 6 \\ ${ }^{1}$ AEMET, Palma, Spain \\ ${ }^{2}$ Météo-France, Toulouse, France \\ ${ }^{3}$ University of the Balearics Islands, Palma, Spain \\ ${ }^{4}$ AEMET, Madrid, Spain \\ ${ }^{5}$ EUCOS, DWD, Offenbach, Germany \\ ${ }^{6}$ ECMWF, Reading, UK
}

Received: 25 March 2011 - Revised: 22 May 2011 - Accepted: 10 June 2011 - Published: 1 September 2011

\begin{abstract}
Adaptive observation is an approach to improving the quality of numerical weather forecasts through the optimization of observing networks. It is sometimes referred to as Data Targeting (DT). This approach has been applied to high impact weather during specific field campaigns in the past decade. Adaptive observations may involve various types of observations, including either specific research observing platforms or routine observing platforms employed in an adaptive way. The North-Atlantic TReC 2003 and the EURORISK-PREVIEW 2008 exercises focused on the North-Atlantic and Western Europe areas using mainly routine observing systems. These campaigns also included Mediterranean cases.

The most recent campaign, DTS-MEDEX-2009, is the first campaign in which the DT method has been used to address exclusively Mediterranean high impact weather events. In this campaign, which is an important stage in the MEDEX development, only operational radiosonde stations and commercial aircraft data (AMDAR) have provided additional observations. Although specific diagnostic studies are needed to assess the impact of the extra-observations on forecast skill and demonstrate the effectiveness of DTS-MEDEX-2009, some preliminary findings can be deduced from a survey of this targeting exercise.

After a description of the data targeting system and some illustrations of particular cases, this paper attempts some comparisons of additional observation needs (through effectively deployed radio-soundings) with sensitivity climatologies in the Mediterranean. The first step towards a sensitivity climatology for Mediterranean cases of high im-
\end{abstract}

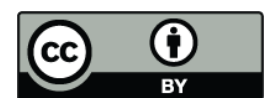

Correspondence to: A. Jansa

(ajansac@aemet.es) pact weather is indirectly given by the frequency of extrasoundings launched from the network of radiosonde stations involved in the DTS-MEDEX-2009 campaign.

\section{Introduction}

One of the main sources of errors in numerical weather prediction is the inaccuracy in the description of the model's initial conditions (Zhu and Thorpe, 2006). Adaptive observation (or data targeting) attempts to predict where additional observations should be deployed in order to minimize the impact of analysis inaccuracies on the subsequent forecast (Langland, 2005; Buizza et al., 2007; Kelly et al., 2007).

Initial conditions are produced by assimilating recent observations together with an earlier short-range forecast which serves as background information. A lack of observations and approximations in the data assimilation procedures inevitably lead to imperfect initial conditions and subsequently to forecast errors, especially when initial errors are located in so-called sensitive regions. Sensitive areas are the places where small changes in the initial conditions have the strongest impact on the forecast of interest (i.e., with respect to which the sensitivity has been computed) (Rabier et al., 1993). When focusing on a specific weather phenomenon in the forecast (a given time-range and localized area of interest), the sensitive areas are likely to be rather compact. In these areas, a small analysis error may lead to a large forecast error (Rabier et al., 1996).

An increase in observation density is likely to reduce potential analysis errors by introducing more information about the real state of the atmosphere. When considering high impact weather (HIW hereafter), generally with low

Published by Copernicus Publications on behalf of the European Geosciences Union. 
predictability, the key point is to predict where the sensitive areas are likely to appear in the near future. Adaptive observation does this and then initiates the real-time deployment of additional observations in the identified sensitive areas (Gelaro et al., 2010).

The DTS (for Data Targeting System) is based on this philosophy, oriented towards the improvement of specific weather forecast cases. The DTS-MEDEX-2009 campaign is a field experiment in which the adaptive observation concept was applied to operational observing systems (radiosoundings and commercial aircraft data - AMDAR) to test the improvement in forecasting cases of HIW related to cyclones in the Mediterranean basin, during the autumn 2009.

Moreover, running a DTS for a whole season (i.e., over a large set of weather situations of interest) helps to build a data series long enough to tackle climatological issues. When considering the campaign as a whole, DTS-MEDEX-2009 can provide a new approach to the sensitivity climatology for HIW in the Mediterranean, complementing former approaches. DTS-MEDEX-2009 is in both senses (data targeting \& HIW watch) a culmination of the development of the international MEDEX project (http://medex.aemet.uib.es).

This paper contains a description of the DTS procedures (Sect. 2) which are illustrated with a particular weather case. Some details about the DTS-MEDEX-2009 campaign follow in the third section. Initial considerations about the cases selected during the campaign, including types and geographical distribution, are presented in Sect. 4. Section 5 describes the inference about the climatology of sensitive areas by considering the geographical distribution of the frequency of additional observations (extra-soundings). A comparison with some previous sensitivity climatologies is presented in Sect. 6 and some conclusions (Sect. 7) close the paper.

\section{The DTS procedure}

The DTS software was first developed at ECMWF in 2007 in the context of the FP7 project EURORISK-PREVIEW 2008, in collaboration with the Met Office (Prates et al., 2009). A first test campaign called EURORISK-PREVIEW 2008 took place from March to December 2008. The DTS-MEDEX2009 campaign was possible thanks to the support of both ECMWF (with the DTS software) and EUCOS facilities and funding for conducting extra observations (EUMETNET). The following paragraph describes how the DTS was operating.

A specific day-by-day weather watch was arranged including several teams of forecasters/scientists (called the members, hereafter) in different centres for the duration of the campaign. The DTS provided the members with deterministic and probabilistic forecasting products, based on both ECMWF and UK Met Office weather prediction models. Other NWP products were also used in the various regional and national meteorological services which participated in the campaign.

Considering the forecast weather situation, any member could propose a so-called targeting case. Such a case was defined by a verifying time (VT) at which a phenomenon of interest was likely to occur in a limited area (verifying area, noted VA) within the region of interest (the Mediterranean basin). Observing (or targeting) times (TT) were introduced between the initial (analysis) time, (the working day, by default, noted AT) and the verifying time. Each time triplet AT, TT, VT combined with VA, thus, defines a targeting case. The difference between AT and TT is the so-called leadtime, the difference between TT and VT is called optimization time.

A "lead user" was designated to decide which of the proposed cases should be selected for targeting (taking account of the potential severity and uncertainty in the case, and the availability and cost of additional observations). For each selected case, sensitivities optimized on the TT-VT segment were predicted several hours or a few days in advance (lead-time). The sensitivity area calculations (SAC) helped in defining the areas where additional observations at time TT would most benefit the forecast from that time, valid at time VT in the area of interest. The difference between TT and VT (optimization time) is the time range for the expected improved forecast of the phenomenon under consideration. From the subjective analysis of the SAC results, the "lead user" determined the "targeting area" that is the area in which extra-observations were requested at the TT. The list of the potential requested radio-sounding sites could be refined manually by the lead-user. The DTS system is flexible enough to distinguish requests for radio-soundings and AMDAR into two different areas. AMDAR measurements were the main observing component when the targeting area stretched over the Atlantic where no targetable radiosonde sites are available.

Within the DTS, automated and localized observation requests were then sent to the operational units involved in observation network management. Extra-observations (radiosoundings and AMDAR) at TT were then performed there.

Figures 1 and 2 illustrate the DTS-MEDEX case 1120 through key moments of the DTS procedure. The example refers to a case that was selected on 2 December 2009, characterised by an intense cyclone, centred in Southern Italy, and likely producing heavy rain in the Balkan area and strong wind in the western Mediterranean and the Tyrrhenian. The verifying time (VT) is 5 December 2009 at 00:00 UTC and the selected targeting time (TT) is 3 December 2009 at 18:00 UTC. Figure 1 shows the forecast situation (ECMWF ensemble spread overlaid with the ensemble mean of mean sea level pressure) and the area defined as the verifying area (VT). Figure 2a shows the sensitivity field, as computed by ECMWF using the total energy singular vector (SV) method (Buizza and Montani, 1999), including the targeting area selected by the lead user (light green rectangle). 


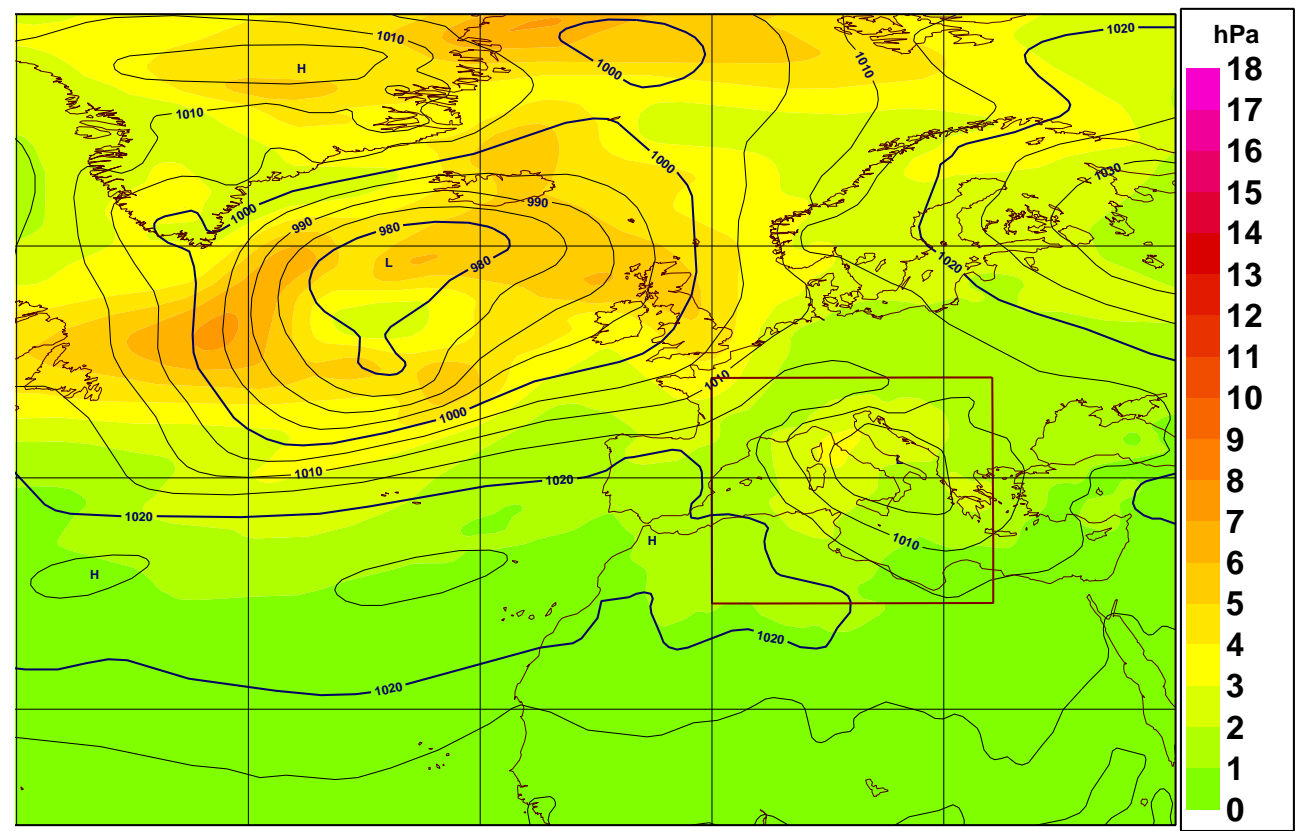

Fig. 1. Example of the DTS procedure applied during the DTS-MEDEX-2009 campaign: case 1120 selected on 2 December 2009. ECMWF ensemble MSLP mean (contours, hPa) and spread (shaded, hPa) forecasts for T + 72, verifying time (VT), 5 December 2009 at 00:00 UTC. The phenomenon of interest is an intense cyclone, centred in Southern Italy, and likely producing heavy rain in the Balkan area and strong wind in the Western Mediterranean and the Tyrrhenian. The selected verifying area (VA) is indicated by a brown box.

Table 1. Geographical distribution of the 89 (simplified) selected cases.

\begin{tabular}{llllllll}
\hline Area & HR & SW & CY & Area & HR & SW & CY \\
\hline Spain & 7 & 8 & 0 & West Med Basin & 0 & 6 & 12 \\
France & 10 & 0 & 0 & Tyrrhenian & 0 & 0 & 8 \\
Italy & 16 & 2 & 0 & Adriatic & 0 & 1 & 6 \\
Balkans & 22 & 2 & 0 & Ionian & 0 & 3 & 5 \\
Greece & 14 & 0 & 0 & Aegean & 0 & 4 & 1 \\
Turkey & 16 & 0 & 0 & East Med Basin & 0 & 0 & 5 \\
Cyprus & 7 & 0 & 0 & & & & \\
Middle East & 4 & 0 & 0 & & & & \\
Algeria & 1 & 4 & 0 & & & & \\
Morocco & 1 & 2 & 0 & & & & \\
\hline
\end{tabular}

Note: $\mathrm{HR}=$ Heavy rain; $\mathrm{SW}=$ Strong wind $\mathrm{CY}=$ Intense cyclone

The ECMWF SV-based guidance, with an easier interpretation, was usually preferred by the "lead user" when defining the targeting area, but in most of the selected cases other targeting guidance was also computed by Météo-France and the University of the Balearic Islands (UIB). The method based on the ensemble transform Kalman Filter (ETKF, Bishop et al., 2001) was used by Météo-France and was displayed on the DTS web page, as in Fig. 2b. The guidance derived from the Kalman Filter Sensitivity (KFS, Bergot and Doerenbecher, 2002) was also computed in Météo-France, but not displayed. Here we include the results from this method for the selected case 1120 in Fig. 2c. This guidance was used locally at Météo-France when the "lead-user" was based in Toulouse.

The University of the Balearic Islands also computed sensitivities for many selected cases (using the MM5 adjoint model, Zou et al., 1997, 1998 and the ensemble sensitivities method of Hakim and Torn, 2008), but the computed fields were not available to the forecasters/scientific teams on real time. Figure $2 d$ shows the results of the ensemble sensitivities for the selected case 1120 .

Extra-soundings and extra-AMDAR observations were requested within the targeting area at the targeting time. The additional data were expected to improve the $30 \mathrm{~h}$ forecast 

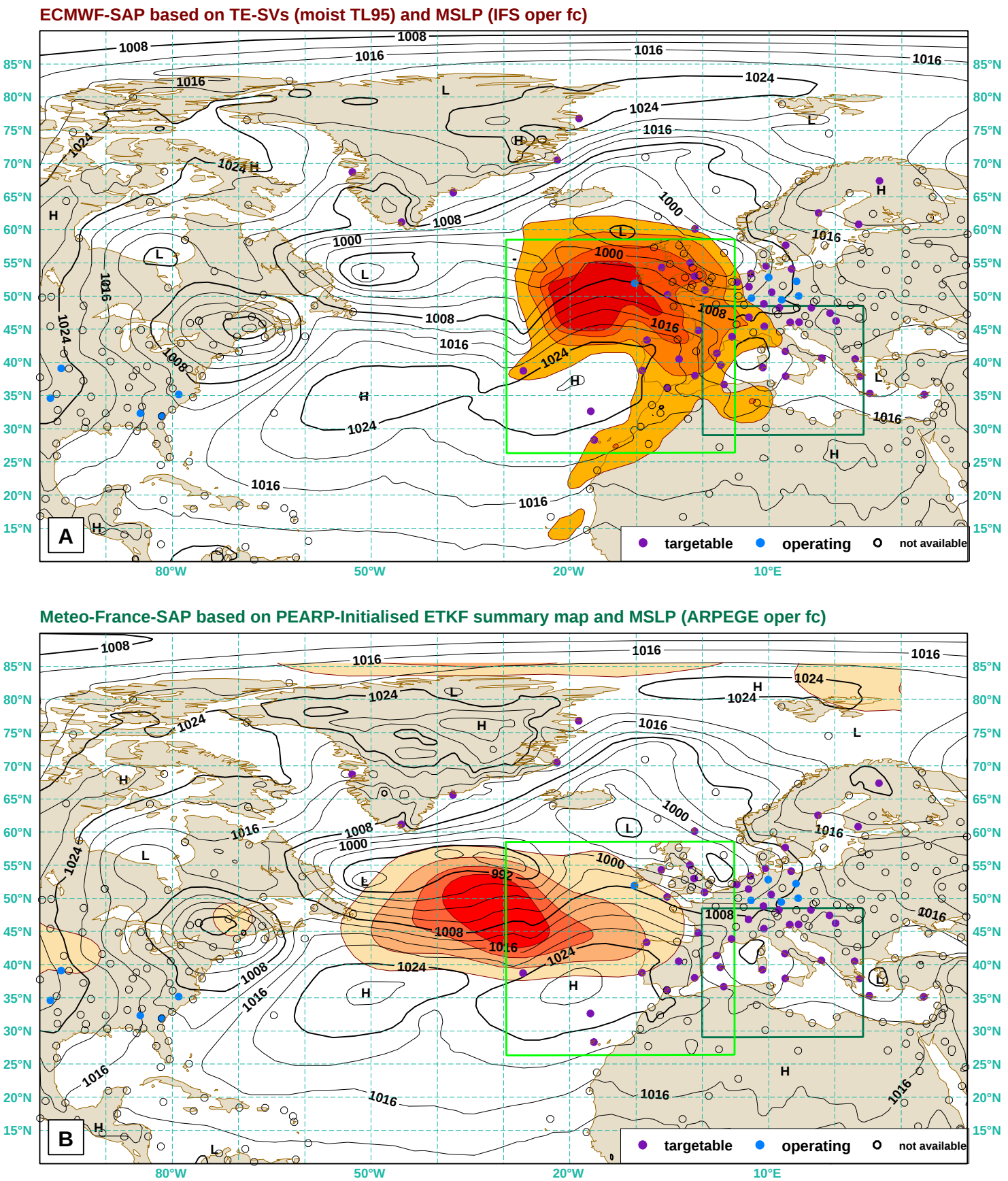

Fig. 2a. Example of fields for targeting guidance (FTG) corresponding to the case number 1120 of the DTS-MEDEX-2009 campaign. Each frame contains a sensitive area (shadings) overlaid with a predicted mean-sea level pressure (MSLP) field to allow some meteorological interpretation. The radio-soundings sites are plotted in violet when targetable, in blue when operating or with a circle when not available for targeting at observation time (TT). The dark green (small) box over the western Mediterranean basin delineate the verification area (VA) valid at verification time (VT). The clear green (large) over western Europe and eastern Atlantic delineate the observation request area. The case has been evaluated on 2 December 2009 (based on the analysis at 00:00 UTC). The lead-time is $42 \mathrm{~h}$, so targeting time is on 3 December 2009 at 18:00 UTC. The targeting guidance (these maps) is valid for that date. Thus, the MSLP fields are $42 \mathrm{~h}$ forecasts. The verification time is on 5 December 2009 at 00:00 UTC. So the meteorological threat was evaluated on $72 \mathrm{~h}$ forecasts. Frame A (upper) shows FTG based on the ECMWF total energy moist-TL95 singular vectors. This FTG was displayed in real time on the DTS web pages. Frame B (lower) is the FTG based on the Météo-France ETKF. The ensemble prediction system used is PEArp (ARPEGE ensemble prediction system). The MSLP is the ARPEGE deterministic operational forecast. This FTG was displayed in real time on the DTS web pages. 

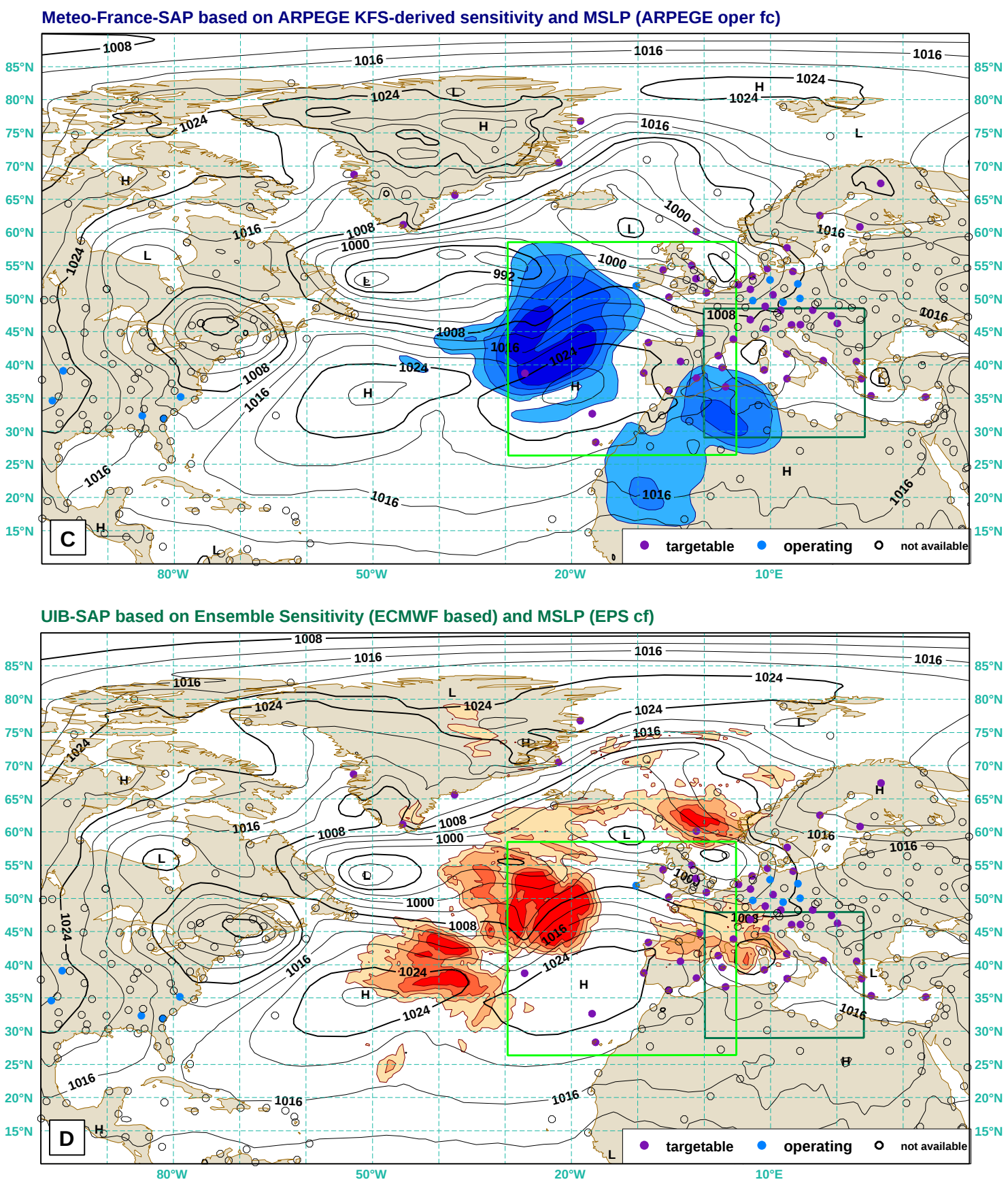

Fig. 2b. Frame C (Upper) is the Météo-France KFS based FTG. This field was available in real time at Météo-France operation centre during the DTS_MEDEX-2009. The MSLP is the ARPEGE deterministic operational forecast. Frame D (Lower) is the UIB Ensemble sensitivity based FTG. This FTG has been simulated a posteriori, but reflects exactly what could have been available during the DTS. The ensemble used here is the ECMWF ensemble (EPS) and the MSLP field is the EPS control forecast.

starting from the analysis of 3 December at 18:00 UTC (TT) and verifying on 5 December at 00:00 UTC (VT).

\section{Some DTS-MEDEX-2009 details}

The DTS-MEDEX-2009 campaign ran from 30 September to 20 December, 2009. Considering that a selected case is defined by a set of verifying time (VT), area of interest (VA) and targeting time (TT), 132 "raw" cases were selected 




Fig. 3. Distribution of the average sensitivity to the forecast of high impact weather in the Mediterranean, indirectly measured through the frequency of extra-soundings request during the DTS-MEDEX-2009 campaign. The isolines are drawn for values of frequency of 5, 10, 15 and 20 requests. The size of the pink squares, in the centre of $2^{\circ} \times 2^{\circ}$ lat-long areas, indicates the frequency of the location in these areas of the centre of the area of interest (or verifying area, VA) defined for the selected cases. The violet star is the "gravity centre" of the locations of the centres of all the areas of interest. All values in this figure are referred to the sub-period 31 October 2009 to 13 December 2009 , in which all the targetable stations (small circles) were available.

during the campaign. This number would be reduced to 89 "simplified" cases if two cases sharing the same VT (the only difference being the TT) are considered as one single case. 484 extra-soundings were successfully launched, of the total 524 requested during the campaign. The extra-soundings were always scheduled at 06:00 or 18:00 UTC, because most of the 50 targetable stations already made operational soundings at 00:00 and 12:00 UTC. The targetable stations were spread over 15 countries in Europe and in Northern Africa (Algeria). Table 2 lists these stations that are also plotted on Figs. 2 and 3.

\section{Characterisation of the selected cases}

The sensitivity fields obtained from a set of selected cases will be used to develop a sensitivity climatology for Mediterranean high impact weather events. To be useful, this set of selected cases must represent, to a certain extent, the variety and geographical distribution of this kind of event. Therefore, we need to examine which kind of cases we had during the campaign.
The comments included by the forecasters and scientists when proposing a case allow us to characterise the kind of event that is involved and the area that is potentially affected by adverse weather. Looking at the total of 89 (simplified) cases that are defined by a verifying time and an area of interest (with one, two or more associated targeting times), 72 are cases associated with heavy rain, 24 are for strong wind and 44 cases in which an intense cyclone is forecasted. Of course, there are cases in which heavy rain and strong wind or heavy rain and intense cyclones or other combinations are expected to occur at the same time. It can be concluded that the sample of cases provided by the campaign represents quite well the type of high impact weather that is frequent in the Mediterranean area, because the proportion between cases of heavy rain, strong wind and intense cyclone in the campaign is not very different from the proportion between cases included in the list of MEDEX selected cases (see MEDEX Data Base in http://medex.aemet.uib.es).

Looking at the geographical distribution of the cases, the area or areas that are expected to be mostly affected by the forecasted high impact weather are also included (usually) 
Table 2. Targetable radio-sounding stations and frequencies of extra-soundings requested (proxy of the sensitivity).

\begin{tabular}{|c|c|c|c|}
\hline Code & Name & Country & Requests \\
\hline 02365 & Sundsvall & Sweden & 1 \\
\hline 02527 & Goteborg & Sweden & 3 \\
\hline 03005 & Lerwick & UK & 3 \\
\hline 03238 & Albemarle & UK & 6 \\
\hline 03354 & Nottingham & UK & 5 \\
\hline 03808 & Camborne & UK & 10 \\
\hline 03882 & Herstmonceux & UK & 8 \\
\hline 03918 & Cator Bay & UK & 9 \\
\hline 04270 & Narsarsuaq & Greenland & 2 \\
\hline 04339 & Scoresbysund & Greenland & 0 \\
\hline 04360 & Tasiilaq & Greenland & 1 \\
\hline 06260 & De Bilt & Netherlands & 7 \\
\hline 06610 & Payerne & Switzerland & 8 \\
\hline 07510 & Bordeaux & France & 17 \\
\hline 07645 & Nimes & France & 15 \\
\hline 08001 & La Coruna & Spain & 18 \\
\hline 08190 & Barcelona & Spain & 19 \\
\hline 08221 & Madrid & Spain & 21 \\
\hline 08302 & Palma & Spain & 18 \\
\hline 08430 & Murcia & Spain & 18 \\
\hline 08495 & Gibraltar & Gibraltar (UK) & 18 \\
\hline 08508 & Lajes & Açores (Portugal) & 5 \\
\hline 08522 & Funchal & Madeira (Portugal) & 5 \\
\hline 08579 & Lisboa & Portugal & 16 \\
\hline 10035 & Schleswig & Germany & 5 \\
\hline 10184 & Greifswald & Germany & 5 \\
\hline 10200 & Emden & Germany & 6 \\
\hline 10410 & Essen & Germany & 6 \\
\hline 10548 & Meiningen & Germany & 6 \\
\hline 10739 & Stuttgart & Germany & 5 \\
\hline 10868 & Muenchen & Germany & 4 \\
\hline 11035 & Wien & Austria & 5 \\
\hline 12843 & Budapest & Hungary & 5 \\
\hline 12982 & Szeged & Hungary & 6 \\
\hline 14015 & Ljubljana & Slovenia & 3 \\
\hline 16044 & Udine & Italy & 7 \\
\hline 16080 & Milano & Italy & 12 \\
\hline 16245 & Pratica di mare & Italy & 7 \\
\hline 16320 & Brindisi & Italy & 6 \\
\hline 16429 & Trapani & Italy & 14 \\
\hline 16560 & Cagliari & Italy & 15 \\
\hline 16622 & Thessaloniki & Greece & 3 \\
\hline 16716 & Athinai & Greece & 3 \\
\hline 16754 & Heraklion & Greece & 4 \\
\hline 17607 & Athalassa & Cyprus & 0 \\
\hline 60018 & Tenerife & Canary Is. (Spain) & 6 \\
\hline 60390 & Dar-el-Beida & Algeria & 18 \\
\hline \multicolumn{3}{|l|}{ total } & 384 \\
\hline
\end{tabular}

in the notes written together with a case proposal. As with the type of event, a case may be associated with several geographical areas at the same time. Table 1 summarizes the geographical distribution and type of the selected events.

Although the distribution of the types of events can be considered as reasonably representative for the high impact phenomena in the Mediterranean, the geographical distribution of the events seems to be quite biased: the concentration of phenomena in the central Mediterranean area looks excessive, when compared to the number of events affecting the western Mediterranean basin and countries. Is this due to the peculiar 2009 season? This bias has to be accounted for when interpreting the sensitivity climatology we present next.

\section{Frequency of extra-sounding requests: a proxy for the sensitivity climatology}

According to the DTS procedure described in Sect. 2, the extra-soundings are only requested from targetable stations located in the area selected by the lead user as the targeting area. This consensus (partly subjective) area is delineated after consideration of the distribution of the sensitivities given by several methods, particularly by the ECMWF SV method. The introduction of a subjective component in the definition of the most sensitive areas is not necessarily bad with regard to the construction of a climatology of the sensitivity (Homar and Stensrud, 2008). In general, the higher the frequency of extra-soundings in a targetable station the higher the sensitivity in the area where this station is located. Therefore, a map of the frequency of extra-soundings may be considered as a map of sensitivity climatology (mainly based on the ECMWF SVs and seen through a human filter).

In order to apply the former assessment, not the whole DTS-MEDEX-2009 campaign can be used, because during the first month (30 September to 30 October) not all the targetable stations were ready to be requested and, therefore, the frequency of requests between stations could not be comparable. To avoid this effect, we have only used the common period in which all the selected stations were enabled, that is, from 31 October to 13 December. Since 13 December more extra-soundings were not requested due to the exhaustion of the economic budget. The cases selected on 30 October can be included for the homogenous sub-period because extrasoundings for a case cannot be requested for the same day of the case selection. This sub-period includes 68 selected cases, which is a significant part of the total.

Table 2 gives the frequency of requests of extra-sounding in all the selected stations that were requested at least once during the whole campaign and it is referred to the sub-period in which all the targetable stations were available.

The forecast range to which the sensitivity refers, that is the difference between the targeting time (TT) and the verifying time (VT) is mostly $30 \mathrm{~h}$. Note that some of the $89 \mathrm{sim}$ plified selected cases of the whole campaign have more than 
Table 3. Forecasting ranges for the 132 distinct raw cases of the whole campaign.

\begin{tabular}{llllllllllll}
\hline Range (h) & 06 & 12 & 18 & 24 & 30 & 36 & 42 & 48 & 54 & 60 & total \\
\hline Cases & 0 & 0 & 34 & 0 & 60 & 0 & 32 & 0 & 6 & 0 & 132 \\
\hline
\end{tabular}

one TT, that is, more than one forecast range. In fact, the number of selected cases of the whole campaign is 132 raw cases, if a case is considered being defined by a set of distinct verifying time, verifying area and targeting time (see Sect. 3). The forecast ranges for all 132 raw cases are distributed as shown in Table 3. Ranges of multiples of $12 \mathrm{~h}$ are not possible because the VT is always 00:00 or 12:00 UTC and the TT is always 06:00 or 18:00 UTC. There are no substantial differences when taking only the sub-period 30 October to 13 December (not shown).

In Fig. 3, we have also represented the frequency of the location of the centres of the verifying areas in squares of $2^{\circ} \times 2^{\circ}$ lat-long, for the sub-set of 68 selected cases, corresponding to the sub-period. This frequency is represented by the size of the pink squares. The violet star in the figure is the "centre of gravity" of the locations of the centres of all the verifying areas. The bias of the geographical distribution of the whole set of selected cases mentioned in Sect. 4, Table 1, is also quite apparent for the sub-set of cases corresponding to the homogeneous sub-period, according to Fig. 3. The high concentration of the verifying areas is in the zone of the central Mediterranean, according to the concentration in this zone and in the Balkans of the areas potentially affected by high impact weather.

From Fig. 3, the average sensitivity for forecasting high impact Mediterranean weather has its maximum values in central Spain, with an extension to the area of high sensitivity to the whole Spain, Portugal, southern France and Maghreb. This result has to be interpreted taking into account the bias already mentioned. In any case, the average sensitivity is very light in the eastern Mediterranean zones, even when a significant number of selected cases are geographically located in those zones. The zone of highest sensitivity is clearly to the west of the zone of maximum frequency of cases. The Atlantic islands show little sensitivity, but this is probably an effect of the bias.

\section{Comparison with other sensitivity climatologies}

The first comparison of our results can be made with the work done by Marseille and Bouttier for EUCOS (Marseille and Bouttier, 2000). They produced seasonal sensitivity climatology for 2 day forecasts, based on daily sensitivity computations using total energy over a wide area (northern Europe and southern Europe). The average sensitivity for southern Europe (that can be compared to our Mediterranean area) in summer has a quite similar distribution to our approach, Fig. 3, with a maximum of sensitivity centred in the southern Iberian Peninsula. High values of the average sensitivity are more spread in winter, extending over large Atlantic areas and with maxima centred in the eastern Iberian Peninsula, northern Italy and south-west of Ireland. However, these results are computed for all weather types in southern Europe, and are not specific to adverse weather in the more limited Mediterranean area.

In the framework of MEDEX, several attempts have been made to produce a sensitivity climatology for high impact weather in the Mediterranean. In view of the difficulty consistently identifying different types of high impact weather (heavy rain, strong wind and intense cyclones), several approaches have been made which reduce the problem to the construction of a sensitivity climatology of intense cyclone events (Homar et al., 2006, 2007; Jansa and Homar, 2006; Garcias and Homar, 2009). In these approaches, instead of the total energy, the function of the weather state, which forecasting tries to improve (through data targeting), is the sea level pressure. The forecast ranges that are considered are up to 48 hours. All in all, their results always indicate high sensitivity towards the Iberian Peninsula and the Maghreb, although the sensitivity is also very high towards the Alpine region and the Atlantic zones for longer time-spans.

\section{Conclusions}

The DTS-MEDEX-2009 showed that such an adaptive observation system interfaced with flexible routine observing systems can be run on a collaborative basis. In this context, the "observation need versus weather threat" paradigm remains higher than the national level, which implies that supranational structures such as EUMETNET are essential to support the deployment of additional observations. After the DTS-MEDEX-2009, future adaptive observing strategies in the Mediterranean should be oriented to complement the subsynoptic/mesoscale observation network. That could be implemented during the HyMeX special observing period that will take place in 2012 and 2013 (http://www.hymex.org). Moreover, in the HyMeX context, the collaborative effort on observation means should be more widely extended to south Mediterranean countries. But prior to a HyMeX effective implementation, it is critical to evaluate whether the campaign did effectively improve NWP products over the period. 
DTS-MEDEX-2009 has provided a new approach to the average sensitivity distribution for a set of cases related to high impact weather in the Mediterranean (heavy rain, strong wind and intense cyclones). It is the only approach specific to this kind of weather and to the three main types of high impact weather at the same time.

The sensitivities for a forecast range (or an evolution time) of of 18,30 or $42 \mathrm{~h}$, mainly $30 \mathrm{~h}$, are most frequently located in the Iberian Peninsula and the Maghreb, followed by France and northern Italy. Although there are selected cases for the whole Mediterranean area, the frequency of appearance of cases of interest seems to be biased towards a concentration higher than the usual in central Mediterranean. This may have some impact on the distribution of sensitive areas. However, our results correspond reasonably well with other studies of average sensitivity for the Mediterranean (concerning the general weather forecasting and the intense cyclones events).

Soundings, extra-soundings and AMDARs in all of the areas identified as highly sensitive (including North-African countries) are especially important to document the short range evolution of the Mediterranean high impact weather cases.

\section{Appendix A}

\section{Abbreviations}

\begin{tabular}{|c|c|c|}
\hline AMDAR & $=$ & Aircraft Meteorological Data Relay \\
\hline AT & $=$ & Working day \\
\hline DT & $=$ & Data Targeting \\
\hline DTS & $=$ & Data Targeting System \\
\hline ECMWF & $=$ & $\begin{array}{l}\text { European Centre for Medium } \\
\text { Range Weather Forecasting }\end{array}$ \\
\hline ETKF & $=$ & Ensemble Transform Kalman Filter \\
\hline EUCOS & $=$ & $\begin{array}{l}\text { The EUMETNET Composite } \\
\text { Observing System }\end{array}$ \\
\hline EUMETNET & $=$ & European Meteorological Network \\
\hline $\begin{array}{l}\text { EURORISK/ } \\
\text { PREVIEW }\end{array}$ & $=$ & $\begin{array}{l}\text { a project to develop pre-operational } \\
\text { information services to support the } \\
\text { management of atmospheric, } \\
\text { geophysical and man-made risks at } \\
\text { a European level. }\end{array}$ \\
\hline FTG & $=$ & Fields for targeting guidance \\
\hline HIW & $=$ & High impact weather \\
\hline HyMeX & $=$ & $\begin{array}{l}\text { Hydrological cycle in the } \\
\text { Mediterranean experiment }\end{array}$ \\
\hline KFS & $=$ & Kalman Filter Sensitivity \\
\hline MEDEX & $=$ & $\begin{array}{l}\text { MEDiterranean EXperient on } \\
\text { cyclones that produce high impact } \\
\text { weather in the Mediterranean }\end{array}$ \\
\hline MSLP & $=$ & Mean sea level pressure \\
\hline NWP & $=$ & Numerical Weather Prediction \\
\hline
\end{tabular}

$\begin{array}{ll}\text { PEArp } & =\text { ARPEGE ensemble prediction } \\ \text { SAC } & =\text { Senstem } \\ \text { SV } & =\text { Singular vector } \\ \text { TReC } & =\text { THORPEX Regional Campaign } \\ \text { TT } & =\text { Targeting time } \\ \text { VA } & =\text { Verifying area } \\ \text { VT } & =\text { Verifying time }\end{array}$

Acknowledgements. The authors of this paper are only part of the team that were actively involved in the DTS-MEDEX-2009 campaign. 16 weather services (15 national weather services and one regional weather service, Catalonia) were involved in the deployment of extra-observations from radiosonde sites, providing manpower and part of consumables. $90000 €$ were spent on the rest of the consumables (mainly radio-soundings). This budget line was supported by EUCOS (EUMETNET). 10 teams (in 5 countries) of forecasters/scientists were monitoring the weather forecast evolution in order to issue case proposals when appropriate. The lead users were from AEMET (in October) and from Météo-France (in November and December). Many responsible people, managers, forecasters, scientists and operational staff in numerous institutions and countries have contributed to the success of the campaign and, therefore, they have contributed to make this work (and future work) possible.

This work has received partial support from the MEDICANES/1 CGL200801271 project.

Edited by: A. Bartzokas

Reviewed by: T. S. Karacostas and another anonymous referee

\section{References}

Bergot, T. and Doerenbecher, A.: A study on the optimization of the deployment of targeted observations using adjoint-based methods, Q. J. R. Meteorol. Soc., 128, 1689-1712, 2002.

Bishop, C. H., Etherton, B. J., and Majumdar, S. J.: Adaptive sampling with the ensemble transform Kalman filter. Part I: Theoretical aspects, Mon. Weather Rev., 129, 420-436, 2001.

Buizza, R. and Montani, A.: Targeting observations using singular vectors, J. Atmos. Sci., 56, 2965-2985, 1999.

Buizza, R., Cardinali, C., Kelly, G., and Thépaut, J. N.: The value of observations, II: The value of observations located in singularvector-based target areas, Q. J. R. Meteorol. Soc., 133, 18171832, 2007.

Garcies, L. and Homar, V.: Ensemble sensitivities of the real atmosphere: application to Mediterranean intense cyclones, Tellus, 61A, 394-406, 2009.

Gelaro, R., Langland, R. H., Pellerin, S., and Todling, R.: The THORPEX Observation Impact Intercomparison Experiment, Mon. Weather Rev., 138, 4009-4025, 2010.

Hakim, G. J. and Torn, R. D.: Ensemble Synoptic Analysis.Synoptic-Dynamic Meteorology and Weather Analysis and Forecasting: A Tribute to Fred Sanders, Am. Meteorol. Soc., 440 pp., 2008.

Homar, V., Jansa, A., Campins, J., and Ramis, C.: Towards a climatology of sensitivities of Mediterranean high impact weather - first approach, Adv. Geosci., 7, 259-267, 2006, http://www.adv-geosci.net/7/259/2006/. 
Homar, V., Jans, A., Campins, J., Genovs, A., and Ramis, C.: Towards a systematic climatology of sensitivities of Mediterranean high impact weather: a contribution based on intense cyclones, Nat. Hazards Earth Syst. Sci., 7, 445-454, doi:10.5194/nhess-7445-2007, 2007.

Homar, V. and Stensrud, D.: Subjective versus objective sensitivity estimates: application to a Noth-African ciclogénesis, Tellus, 60A, 1064-1078, 2008.

Jansa, A. and Homar, V.: Climatology of sensitivities of high impact weather in the Mediterranean, Eucos-Report, Eucos Studies Programme, Reading, UK, 2006.

Kelly, G., Thépaut, J.-N., Buizza, R., and Cardinali, C.: The value of observations. I: Data denial experiments for the Atlantic and the Pacific, Q. J. R. Meteorol. Soc., 133, 1803-1815, 2007.

Langland, R. H.: Observation Impact during the North Atlantic TReC-2003, Mon. Weather Rev., 133, 2297-2309, 2005.

Marseille, G. J. and Bouttier, F.: From sensitivity studies to observation planning, EUCOS-Report, Eucos-Rep-030, Reading, UK, 2000 .
Prates C., Richardson, D., and Sahin, C.: Final report of the PREVIEW observation Data Targeting System (DTS), ECMWF Tech. Memo., 581, 2009.

Rabier, F., Courtier, P., Hervéon, M., Strauss, B., and Persson, A.: Sensitivity of forecast error to initial conditions using the adjoint model, ECMWF Tech. Memo., 197, 1993

Rabier, F., Klinker, E., Courtier, P., and Hollingsworth, A.: Sensitivity of forecast errors to initial conditions, Q. J. R. Meteorol. Soc., 122, 121-150, 1996.

Zhu, H. and Thorpe, A.: Predictability of Extratropical Cyclones: The influence of Initial Conditions and Model Uncertainties, J. Atmos. Sci., 63, 1483-1497, 2006.

Zou, X., Vandenberghe, F., Pondeca, M., and Kuo, Y.-H.: Introduction to adjoint techniques and the MM5 adjoint modeling system, NCAR Tech. Note NCAR/TN-435+IA, 1997

Zou, X., Huang, W., and Xiao, Q.: A User's Guide to the MM5 Adjoint Modeling System, NCAR Tech. Note NCAR/TN-437+IA, 1998. 